Article

\title{
Solar-Powered Compaction Garbage Bins in Public Areas: A Preliminary Economic and Environmental Evaluation
}

\section{Poppy Jane Coleman and Long Duc Nghiem*}

School of Civil Mining and Environmental Engineering, University of Wollongong, NSW 2522, Australia; E-Mail: pjc768@uow.edu.au

* Author to whom correspondence should be addressed; E-Mail: longn@uow.edu.au;

Tel.: +61-2-4221-4590; Fax: +61-2-4221-3238.

Received: 16 December 2009 / Accepted: 4 February 2010 / Published: 8 February 2010

\begin{abstract}
An excel-based model was developed to evaluate economic and environmental benefits of the solar-powered compaction garbage bins in public areas in Australia. Input data were collected from Brisbane and Wollongong City councils, and Sydney Olympic Park. The results demonstrate that solar-powered compaction garbage bins would provide environmental benefits in all scenarios. However, results of the economic analysis of the three studied areas varied significantly. The unique situation of Sydney Olympic Park made implementation in that facility particularly appealing. A lower monthly rental cost is needed for the implementation of this novel waste management practice.
\end{abstract}

Keywords: solar-powered compaction garbage bins; public areas; waste management; greenhouse gas emission

\section{Introduction}

Municipal waste management techniques can vary widely between countries and between regions within countries. Europe and several other places around the world favor Envac, an underground system of vacuum pipes to transport waste to landfills or incinerators [1,2]. In Australia, Canada and most of the US, collection by vehicle is the most commonly used form of waste transport. Waste is often managed by local councils or by private companies commissioned by councils [1,3,4]. Responsibility for waste management generally falls under the jurisdiction of local, state and territory governments. Issues within waste management include collecting and dealing with household garbage, 
managing landfill and overseeing the legislative framework to protect human health and the environment. Driven by demand for better efficiency and environmental protection, waste management techniques in Australia have been significantly transformed in recent years. Major changes include the privatization of municipal solid waste management and the adaptation of new technologies such as bin on wheels and fully automated collection vehicles with compaction capacity.

Compaction in waste management has traditionally been utilized during transport and final disposal phases, through the use of compactors in trucks and landfills [1,4]. Compaction in landfills is primarily aimed at minimizing the final volume of waste stored at the site and stabilization of the fill. Garbage collection trucks were fitted with compactors in order to make a greater number of collections on each trip. By utilizing compaction technology at the waste site, the collection frequency could be minimized, reducing the use of collection trucks. This is beneficial from both economic and environmental standpoints, as this project seeks to prove. On-site compaction of waste is not a new concept. However, to date, the use of this concept has largely been restricted to commercial sites with a sufficiently large quantity of waste.

There is an indelible link between waste management and pollution [5,6]. In 2002-2003, Australia generated around 32.5 million tones of waste [6]. Waste management in Australia is accounted for $15 \mathrm{MtCO}_{2} \mathrm{e}$, drawing mostly from breakdown of biologically active material in waste into landfill gas (methane) [6]. This figure does not include any emissions from the collection and transport of waste, which is included under 'transport' in the national greenhouse accounts. Indeed, waste collection can amount to up to $70 \%$ of the total municipal solid waste management budget (mostly in fuel and labor cost) [1,7]. In this context, new technologies are emerging to assist public and private entities with meeting the enhanced productivity and environmental targets. One of such technologies is the solar-powered compaction garbage bin, which has recently been introduced into Australia by Allied Industrial Services.

\section{Solar-Powered Compaction Garbage Bins}

The solar-powered compaction garbage bins are designed to reduce the need to empty waste receptacles in public areas. The bin holds more than six times the volume of the average $120 \mathrm{~L}$ mobile garbage bin, leading to the elimination of at least three out of every four collection trips. This not only reduces operating costs, unsightly litter overflows and public disturbance, but also minimizes emissions from waste-carrying vehicles, further benefiting the environment. The solar-powered compaction garbage bins are equipped with a solar photovoltaic panel and a small battery. The battery is charged during the day allowing the unit to operate during night time. The bins automatically compact the waste when the garbage inside reaches a certain level. As users deposit garbage, it falls into a bin inside the unit. When the level of garbage eventually rises above the top of the inner bin, the garbage interrupts an electric eye beam, triggering the motor to compact the garbage down into the bin, making room for additional garbage. The process repeats automatically as needed until the machine is ready for collection, typically holding about $700 \mathrm{~L}$ of equivalent uncompacted garbage. At that point, a LED light indicator on the front panel goes from green to yellow, notifying staff that the unit is ready for collection. The bins can be color-coded and used for either non-recycling or recycling waste materials. 


\section{Methodology}

\subsection{Model Development}

An excel-based cost-benefit model was developed to evaluate economic and environmental gains of implementing the solar-powered compaction garbage bins for waste management in public areas. Input data were collected from three areas of distinctive demographical characteristics - namely the Brisbane City council, the Wollongong City council, and Sydney Olympic Park. The worksheet sent out for data collection was carefully designed for ease of use (Figure 1). Data required was clearly outlined, with further definition and clarification as required. The volume of data inputs were carefully optimized and only essential data needed for the model were requested. Requested data can be categorized into three components: waste collection, collection vehicles and labors. The cost of waste management consists of the amortization of the collection vehicles, cost of garbage bins, and labor costs. In Australia, Allied Industrial Services plan to lease the solar-powered compaction garbage bins and bundle all maintenance and services into the monthly rental cost. This approach significantly simplifies the cost calculation of the solar-powered compaction garbage bins for both the customers as well as the model used in this study. Carbon dioxide, nitrogen oxides and particulate matter (PM10) emission calculation was directly based on the volume of diesel fuel consumed (Equation 1). Emission factors of low sulfur diesel fuel for carbon dioxide, nitrogen oxides and particulate matter (PM10) were $2.7 \mathrm{~kg} / \mathrm{L}, 0.005 \mathrm{~kg} / \mathrm{L}$, and $0.0002 \mathrm{~kg} / \mathrm{L}$, respectively [5].

$$
\text { Emission }(\mathrm{kg})=\text { Volume of diesel fuel consumed }(\mathrm{kL}) \times \text { Emission Factor }
$$

\subsection{Studied Areas}

Three areas of distinctive demographical characteristics-namely the Brisbane City council, the Wollongong City council, and Sydney Olympic Park-were selected for this study. Brisbane City is Australia's third largest city, with a population of around 1.8 million people. Being situated on the east coast of Queensland, Brisbane is also subject to seasonal tourist activity, meaning a surge in population during the summer months. As such, public waste management in Brisbane must have the capability for significantly increased waste volume, specifically around beaches and other tourist attractions. Wollongong City Council services a resident population of around 200,000. The geography of the greater Wollongong area is such that the bulk of development is along the coastline, caused by the proximity of the escarpment limiting growth to the west. Situated only an hour south of Sydney, Wollongong is a popular destination for day-trip visitors, causing a surge in weekend activity and hence in weekend waste volume. The beachside nature of the area also results in increased tourist population during the summer months. Due to the significant difference between the city centre and the city beach front area, data from Wollongong City council were further divided into Beach and Central collection routes. Consequently, two separate User Data input sheets were obtained from the Wollongong City council. It is noted that the waste service areas of both Brisbane and Wollongong were limited only to the city centre of high concentration of pedestrian activities. In contrast to the two city councils, Sydney Olympic Park is not host to a permanent resident population. It is rather a 
destination for large-scale events and tourism. Because of this, the waste generation volume for the area varies substantially from day to day, depending on the nature and scale of scheduled events.

\subsection{Simulation Scenarios}

Three scenarios were applied to each of the three areas studied as a part of the project. The scenarios were formulated to demonstrate a range of benefits that can be achieved through the utilization of the solar-powered compaction garbage bins. These scenarios are as below.

No reduction in collection points (scenario 1): The individual bins were directly replaced with solar-powered compaction garbage bins, leaving the same number of bins after implementation that existed before. The rental rate for each fully maintained solar-powered compaction garbage bins was fixed at \$300 per month, comparably to the \$297 per month currently charged by Allied for orders between 90 and 100 units. This higher rental was adopted to show maximum economic costs, as monthly rental rate would decrease with higher volume orders. Collection frequency was varied to suit the increased volume of the solar-powered compaction garbage bins.

Reduction in collection points (scenario 2): Due to increased capacity of solar-powered compaction garbage bins, the number of individual bins was reduced by $40 \%$, with collection frequency varied to suit the new collection volume. The rental rate was again fixed at $\$ 300$ per month for each solar-powered compaction garbage bin.

Break-even determination (scenario 3): Keeping the number of collection points constant at the current value, an economic break-even point was determined by varying the monthly rental rate of the solar-powered compaction garbage bins.

\section{Results and Discussion}

\subsection{Input Data}

Input data provided by Brisbane City council, Wollongong City council, and Sydney Olympic Park Authority are presented in Table 1. At the time of this study, Brisbane City council had 10 solar-powered compaction garbage bins on trial. Both Wollongong City council and Sydney Olympic Park have not adapted this technology. With a few exceptions, waste management in public areas by all three areas was quite comparable. Diesel collection trucks were used in all cases. It is noteworthy that the upfront capital cost of each standard waste bin included the cost of a security stand, base, and surrounding installation. The trucks used at Wollongong City council were leased at an hourly rate of 35\$/hour. The cost of collection trucks for Wollongong City council was calculated according to the number of collection hours per year. It is assumed that over head has been included in the all-in labor cost. However, this figure did not include overtime and other standard employment entitlements in Australia (sick leave, holidays, doubled salary when working over the weekend or public holidays). 
Table 1. Input data obtained from Brisbane City council, Wollongong City council, and Sydney Olympic Park Authority.

\begin{tabular}{|l|c|c|c|c|}
\hline \multicolumn{1}{|c|}{ Waste collection } & Brisbane & $\begin{array}{c}\text { Wollongong } \\
\text { (Beach) }\end{array}$ & $\begin{array}{c}\text { Wollongong } \\
\text { (Central) }\end{array}$ & SOPA \\
\hline Number of solar-compaction units & 10 & 0 & 0 & 0 \\
\hline Number of Regular Waste Bins & 718 & 491 & 210 & 212 \\
\hline On-Season Weeks of Operation*/Year & 52 & 29 & 52 & 52 \\
\hline Off-Season Weeks of Operation*/Year & 0 & 23 & 0 & 0 \\
\hline Waste Pick-ups per Week (On-Season) & 6 & 6 & 7 & 6 \\
\hline Waste Pick-ups per Week (Off-Season) & 0 & 5 & 0 & 0 \\
\hline Individual Bin Capacity (liters) & 80 & 240 & 240 & 240 \\
\hline Travel time/Waste Collection (hours) & 1.00 & 1.00 & 1.00 & 1.00 \\
\hline Time to Empty Each Waste Bin (mins) & 2 & 2 & 2 & 4 \\
\hline Upfront Capital Cost for Current Waste Bin & $\$ 1,380$ & $\$ 1,325$ & $\$ 1,325$ & $\$ 1,500$ \\
\hline Current Waste Bin Life (years) & 5 & 5 & 5 & 4 \\
\hline Distance travelled/Collection Journey (km) & 70 & 60 & 60 & 37 \\
\hline \multicolumn{1}{|c|}{ Collection vehicles and labor cost } & & & & 5 \\
\hline Total Number of Waste Trucks for Area & 2 & 2 & 5 & 5 \\
\hline Truck Purchase Price & $\$ 250,000$ & $\$ 87,360$ & $\$ 175,664$ & $\$ 250,000$ \\
\hline Truck Lifetime (Years) & 10 & 1 & 1 & 10 \\
\hline Truck General Usage (hours/week) & 56 & 48 & 56 & 75 \\
\hline Truck Fuel Consumption Rate (liters/km) & 0.27 & 6 & 0.22 & 0.27 \\
\hline Diesel Fuel Cost (\$/liter) & $\$ 1.50$ & $\$ 1.35$ & $\$ 1.50$ & $\$ 1.40$ \\
\hline Laborers/Truck & 2 & 4 & 2 & 1 \\
\hline All-in Labor Cost (\$/hour) & $\$ 20$ & $\$ 37$ & $\$ 37$ & $\$ 40.95$ \\
\hline Rubbish Tipping Fee (\$/tip occasion) & $\$ 249$ & $\$ 130$ & $\$ 130$ & $\$ 130$ \\
\hline
\end{tabular}

* The "On-Season" is the period with higher public activity (e.g., summer months), usually requiring higher collection frequency.

\subsection{Same Number of Bins}

In scenario 1, each standard waste bin is be replaced by a solar-powered compaction garbage bin and the collection frequency is reduced to one per week for Brisbane City council and two per week for all other areas. This scenario results in a severe financial penalty for all investigated areas, reflected by negative values of cost saving (Table 2). At the expense of this financial penalty, considerable environmental gains can also be seen in Table 2. Nevertheless, even if monetary values can be assigned to such environmental benefits, it is unlikely that they can offset the financial penalty under this scenario. As can be seen in Table 2, Sydney Olympic Park is the most appealing candidate for implementation of the solar-powered compaction garbage bins. It is noteworthy that significant amenity value of the solar-powered compaction garbage bins was not included in this simulation. More importantly, the storage volume of the solar-powered compaction garbage bin was under utilized in this scenario to ensure collection frequency of one or two per week to avoid the decomposition of waste. In addition, the monthly rental rate of the solar-powered compaction garbage bin was set at an 
introductory level of 300\$ per month. The monthly rental rate is rather elastic and this number could be significantly lower with an increased market size.

Table 2. Economic and environmental benefits when replacing the same number of standard waste bins with solar-powered compaction garbage bins.

\begin{tabular}{lcccc}
\hline Waste Collection & Brisbane & $\begin{array}{c}\text { Wollongong } \\
\text { (Beach) }\end{array}$ & $\begin{array}{c}\text { Wollongong } \\
\text { (Central) }\end{array}$ & SOPA \\
\hline Cost saving (\$/year) & $-1,116,580$ & $-1,712,838$ & $-407,283$ & $-300,216$ \\
\hline Cost saving (as percentage) & $-132 \%$ & $-164 \%$ & $-95 \%$ & $-57 \%$ \\
\hline $\mathrm{CO}_{2} \mathrm{e}$ emission saving (tonnes/year) & 6.55 & 13.2 & 7.73 & 5.57 \\
\hline PM10 emission saving (kg/year) & 0.38 & 0.77 & 0.45 & 0.32 \\
\hline NOx emission saving (kg/year) & 12.0 & 24.1 & 14.2 & 10.2 \\
\hline
\end{tabular}

\subsection{Reduction in Number of Bins}

As discussed above, keeping the same number of waste bins would result in an under-utilization of the solar-powered compaction garbage bin storage capacity. An informal survey of the studied areas reveals that it is quite common to bundle two or more waste bins together to service very high pedestrian activity spots. Scenario 2 was, therefore, developed to simulate a $40 \%$ reduction in bin numbers with the integration of the solar-powered compaction garbage bins. This scenario has a significant impact on cost and environmental impacts in other council areas. Sydney Olympic Park would break even, while other areas showed losses of 27\% (Wollongong Beach), 44\% (Wollongong Central) and 86\% (Brisbane). All studied areas and collection runs showed reductions in greenhouse gas emissions of over 50\%, with Brisbane showing the highest saving, at $83 \%$ compared with current levels.

\subsection{Break-Even Determination}

Using the goal seek function of excel, the solar-powered compaction garbage bin rental rate required to achieve break-even was calculated. This scenario did not vary the number of bins and utilized the collection regime for the solar-powered compaction garbage bins that was generated in scenario 1. As such, the environmental benefits of this scheme are identical to those in the first scenario. The rental rates required by each council are outlined in Figure 1. The two main drivers for the development of the solar-powered compaction garbage bins product were environmental as well as financial benefits in solid waste management in an urban context. With the reduction in emissions already demonstrated, this scenario addresses the profit criteria, outlining the target rental rate for profitability in each studied area. Of particular interest is the result for Sydney Olympic Park, where a minimal reduction in rental rate provides a break-even. A rental rate of 179 \$ per month (Figure 1) can be achievable given the number of 210 solar-powered compaction garbage bins required for Sydney Olympic Park. It is noted that the current rental rate of $300 \$ /$ month recommended by Allied Industrial Services was based on an introductory sale volume of 90-100 units. Results reported here can also 
provide an indication of a priority order to develop a market for the solar-powered compaction garbage bins.

Figure 1. Break even monthly rental rate of the solar-powered compaction garbage bin.

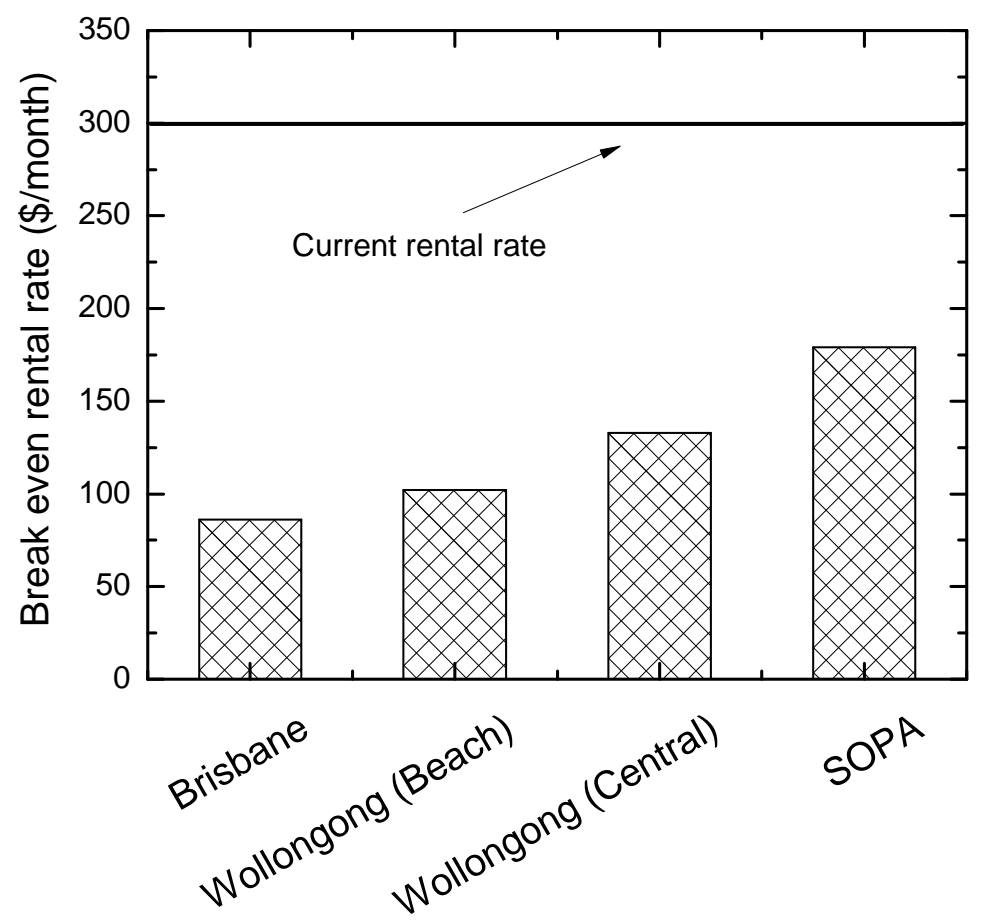

\subsection{Overall Evaluation}

Due to significant differences in input parameters between the various studied areas, results for each area varied considerably. Nevertheless, substantial environmental benefits of the incorporation of the solar-powered compaction garbage bins into local council collection practices can be demonstrated in all cases with all simulated scenarios. Furthermore, given the increasing emphasis put on climate change and greenhouse gases by the public and government bodies, the value of minimizing emissions is set to increase exponentially in coming years. It is also anticipated that such a value would eventually have a dollar value (either through incentives or trading schemes), cementing a relationship between environmental and economic savings.

In order to identify areas in which future improvements should be focused, the model was analyzed to determine sensitive input parameters. Any change in these variables results in a multiplied change in outputs, mostly in economic benefits/impacts. Four sensitive parameters were identified through this process, namely monthly rental rate, labor cost, fuel cost, and number of service bins (or number of collections/pickups). The significance of the first three parameters is quite apparent. As discussed above, the month rental rate can be further reduced depending on market conditions. Future increase in labor cost and fuel cost will be favorable for the implementation of the solar-powered compaction garbage bins. Results obtained from three different simulated scenarios consistently produce the same order of preference for the implementation of the solar-powered compaction garbage bins in the order of Sydney Olympic Park > Wollongong (Central) > Wollongong (Beach) > Brisbane. This can be 
attributed in part to the number of service bins used in these four case studies. Sydney Olympic Park and Wollongong (Central) both have a small number of service bins (212 and 210 bins, respectively). The time to empty each standard waste bin was four minutes at Sydney Olympic Park and two minutes at Wollongong (Central) (see Table 1). In identifying Sydney Olympic Park as the greatest potential beneficiary from the solar-powered compaction garbage bins, it is noteworthy that other councils participating in the study can be worthy candidates for this technology when market conditions become favorable.

\section{Conclusions}

An excel-based model was developed to evaluate economic and environmental benefits of the solar-powered compaction garbage bins in public areas in Australia. Input data were collected from Brisbane and Wollongong City councils, and Sydney Olympic Park. The results clearly demonstrated that solar-powered compaction garbage bins would provide environmental benefits across the board. However, a reduction in the monthly rental cost would be required to facilitate the use of the solar-powered compaction garbage bins in public areas. The solar-powered compaction garbage bins seems favorable in areas where a small number of waste bins is required.

\section{Acknowledgements}

Allied Industrial Services is acknowledged for the provision of a Work-Integrated Scholarship to Poppy Coleman. Brisbane City council, Wollongong City council and Sydney Olympic Park Authority are thanked for the provision of data to this study.

\section{References and Notes}

1. $\quad$ Bilitewski, B.; Härdtle, G.; Marek, K. Waste Management; Springer: New York, NY, USA, 1997.

2. Iriarte, A.; Gabarrell, X.; Rieradevall, J. LCA of selective waste collection systems in dense urban areas. Waste Manag. 2009, 29, 903-914.

3. Dahlen, L.; Vukicevic, S.; Meijer, J.E.; Lagerkvist, A. Comparison of different collection systems for sorted household waste in Sweden. Waste Manag. 2007, 27, 1298-1305.

4. Emery, A.; Davies, A.; Griffiths, A.; Williams, K. Environmental and economic modelling: A case study of municipal solid waste management scenarios in Wales. Resour. Conserv. Recycl. 2007, 49, 244-263.

5. Beer, T.; Grant, T.; Morgan, G.; Lapszewicz, J.; Anyon, P.; Edwards, J.; Nelson, P.; Watson, H.; Williams, D. Comparison of Transport Fuels; Australian Commonwealth Scientific and Research Organization (CSIRO): Aspendale, Australia, 2004.

6. Australian Greenhouse Office-Factors and Methods Workbook; Australian Greenhouse Office: Canberra, Australia, 2004. 
7. Tavares, G.; Zsigraiova, Z.; Semiao, V.; Carvalho, M.G. Optimisation of MSW collection routes for minimum fuel consumption using 3D GIS modelling. Waste Manag. 2009, 29, 1176-1185.

(C) 2010 by the authors; licensee Molecular Diversity Preservation International, Basel, Switzerland. This article is an open-access article distributed under the terms and conditions of the Creative Commons Attribution license (http://creativecommons.org/licenses/by/3.0/). 